\title{
Caracterização de Resíduos de Copolímeros de Etileno-Acetato de Vinila - EVA
}

\author{
Ademir J. Zattera, Otávio Bianchi \\ Departamento de Engenharia Química, UCS \\ Mara Zeni \\ Departamento de Física e Química, UCS \\ Carlos A. Ferreira \\ Escola de Engenharia, UFRGS
}

Resumo: O poli[(etileno)-co-(acetato de vinila)] (EVA) possui grande aplicação na indústria calçadista, sendo utilizado na confecção de placas expandidas para posterior corte de palmilhas e entressolas. Estudos realizados na região sul do Brasil mostraram que os resíduos gerados pela indústria calçadista foram superiores a 200 toneladas/mês em 2001, sendo o maior volume oriundo de recortes de placas expandidas. Por isso, o objetivo deste trabalho foi o de caracterizar resíduos de EVA de chapas expandidas, visando à reciclagem mecânica desse material. Análises em MEV demonstraram que o resíduo de EVA apresenta uma morfologia microcelular que é destruída após o processo de moagem. O resíduo de EVA moído apresenta duas fases, uma reticulada (matriz) e uma não-reticulada (dispersa). O resíduo de EVA apresentou teor de gel de aproximadamente $75 \%$ em massa, cerca de $20 \%$ em massa de acetato de vinila (VAc), fora processado a partir de EVA com aproximadamente $28 \%$ de VAc e possui teor de carga inorgânica de $20 \%$ em massa, segundo análises em TGA. O EVA resíduo apresentou maiores valores de módulo elástico e de dureza, e menores valores de elongação na ruptura e de resistência ao impacto Izod. O custo energético da moagem do resíduo de EVA foi calculado como sendo inferior a 5\% do valor do EVA virgem.

Palavras-chave: EVA, chapas expandidas.

\section{Characterization of Ethylene-Vinyl Acetate Copolymer (EVA) Residues}

Abstract: Poly[(ethylene)-co-(vinyl acetate)] (EVA) has large application in the shoes industries, especially as expanded sheets, in order to produce insoles and innersoles. Studies carried out in the south region of Brazil in 2001 have demonstrated that the residues generated by shoes industries were higher than 200 ton/month, the major part of which is composed by EVA expanded sheets. With this in mind, the objective of this work was to characterize the residues of expanded EVA and also to analyze the milling cost in order to make the recycling possible. The EVA residues presented originally a microcellular structure, which was destroyed after milling, according to SEM analysis. The EVA powder was found to be composed by two phases: a crosslinked phase $(75 \mathrm{wt} \%)$ and a soluble one $(25 \mathrm{wt} \%)$. The VAc content in EVA residues was found to be around $20 \mathrm{wt} \%$ and it is believed that the EVA had originally ca. $28 \mathrm{wt} \%$ of VAc before the crosslinking process, according to the TG analysis. Besides, it was found that the crosslinked structure of EVA residues make them stiffer than virgin EVA used for comparison, according to mechanical tests. The milling cost was estimated to be less than $5 \%$ compared to the virgin EVA.

Keywords: EVA, expanded sheets.

\section{Introdução}

O copolímero poli[(etileno)-co-(acetato de vinila)] (EVA) é formado pelo encadeamento de seqüências aleatórias de polietileno e poli(acetato de vinila) (PVAc). Suas propriedades são geralmente intermediárias, quando comparadas as dos componentes puros, o que se deve à sua complexa morfologia, que é composta por uma fase cris- talina, contendo unidades metilênicas, uma região interfacial, com segmentos metilênicos e segmentos de acetato de vinila (VAc), e uma fase amorfa, com segmentos metilênicos e unidades de $\mathrm{VAc}^{[1]}$.

Se comparado com um PEBD de mesma massa molar, o EVA apresenta maior valor de elongação na ruptura e de resistência ao impacto, e menor módulo de elasticidade. $\mathrm{O}$ EVA com teores de acetato de vinila entre $18-28 \%$ em

Autor para correspondência: Ademir J. Zattera, Departamento de Engenharia Química, CCET, Universidade de Caxias do Sul, Rua Francisco Getúlio Vargas 1130 - Petrópolis, CEP: 95001-560, Caxias do Sul, RS. E-mail:ajzatter@ucs.br 
massa possui grande aplicação na indústria de calçados, sendo a maior parte utilizada na confecção de placas expandidas para estampagem de palmilhas, entressolas, confecção de so$\operatorname{lados}^{[2]}$, ou de variados artigos como: viseiras, brinquedos, material didático, etc. ${ }^{[3-5]}$. Os solados produzidos com EVA expandido possuem densidades menores comparados ao SBR ou ao PVC expandido, e apresentam células fechadas, o que diminui a absorção de água.

Estudos realizados sobre o EVA têm mostrado o seguinte crescimento de consumo: 8.142 toneladas no ano de 1985, passando para 39.103 tonelada no ano de 1999 e para de 45.780 toneladas em 2003 ${ }^{[6]}$. Segundo a Associação Brasileira da Indústria de Plásticos (ABIPLAST), em 2003 o consumo de resinas termoplásticas no Brasil foi da ordem de 3.817.000 toneladas. O polietilieno representou a maior porcentagem deste montante, cerca de 39,9\% (1.522.704 toneladas), e o copolímero EVA com um valor de 1,2\% (45.780 toneladas) ${ }^{[6]}$.

A indústria de calçados da região do Vale do Rio dos Sinos (Rio Grande do Sul), gerou uma quantidade de resíduos superior a 200 toneladas/mês, de acordo com estudo realizado em 2001 por Serrano ${ }^{[7]}$, o qual identificou 72 componentes poliméricos em diferentes proporções. Os materiais que representaram um volume maior entre estes resíduos eram oriundos do processo de recortes de placas expandidas, constituídas por aproximadamente 3,9\% de EVA, dependendo das características das micro-regiões produtoras de calça$\operatorname{dos}^{[7,8]}$. O processo de corte e acabamento de chapas expendidas de EVA gera uma média de $18 \%$ em massa de material residual, perfazendo o montante estimado no Brasil deste tipo de descarte da ordem de 7.932 toneladas anuais ${ }^{[8]}$. Baseado neste cenário, o objetivo deste trabalho foi o de caracterizar resíduos de EVA provenientes de chapas expandidas quanto à morfologia, propriedades térmicas e propriedades mecânicas e determinar o custo da moagem destes resíduos visando sua reutilização.

\section{Experimental}

\section{Materiais}

O resíduo de EVA utilizado neste trabalho (Figura 1) é oriundo de retalhos provenientes de placas expandidas usadas pela indústria de calçados. Além do EVA, o resíduo pode conter em sua formulação básica os seguintes tipos de aditivos: agente de reticulação, ativadores, agente expansor, cargas e pigmento ${ }^{[3,9,10]}$.

Para fins de comparação foram utilizados dois tipos de EVA, adquiridos da empresa Polietilenos União S/A, com teores de acetato de vinila de 18\% (EVA-18) e 28\% (EVA-28).

\section{Métodos}

\section{Moagem dos resíduos}

Os resíduos de EVA foram moídos utilizando um equipamento do tipo aglomerador desenvolvido na universidade, a velocidade de $1800 \mathrm{rpm}$. A alimentação no moinho foi feita pela parte superior, sendo o material moído retirado gradual-

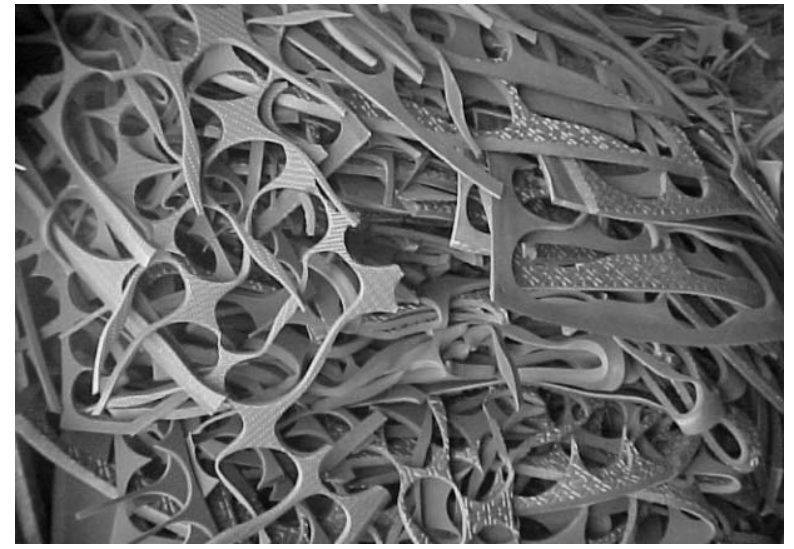

Figura 1. Resíduos da indústria calçadista proveniente do corte de chapas de EVA expandido

mente pela parte lateral inferior, através de uma peneira com granulometria adequada (1,588 $\mathrm{mm}$ de abertura).

\section{Custo energético da moagem do resíduo de EVA}

$\mathrm{O}$ custo energético foi estimado com base na corrente máxima exigida pelo moinho, medida com auxílio de um amperímetro de alicate. A capacidade de processamento do equipamento foi da ordem de $50 \mathrm{~kg} / \mathrm{h}$.

\section{Teor de gel}

A determinação do teor de gel foi realizada de acordo com a norma ASTM D2765. Esta análise é realizada introduzindo-se cerca de 0,3g do material (30-60 mesh) em um compartimento fechado (tela com 120 mesh) disposto no interior de um balão de fundo redondo contendo xileno, o qual é mantido sob ebulição durante 12 horas. A extração foi realizada utilizando-se o resíduo de EVA moído. O material extraído pelo solvente foi recolhido em balão volumétrico e seco sob vácuo em um roto-evaporador (Brinkemann R-110, a $30 \mathrm{rpm} \mathrm{e} 40^{\circ} \mathrm{C}$ ). A secagem do material foi completada em uma estufa a vácuo a $50^{\circ} \mathrm{C}$ por 72 horas. A porção solúvel de EVA será denotada por EVAex e a porção insolúvel (reticulada) por EVAr, no decorrer do texto.

\section{Análise termogravimétrica (TGA)}

Os processos de degradação, os teores de material remanescente e o teor de acetato de vinila (VAC) foram determinados com base na análise termogravimétrica (TGA) das amostras de resíduo de EVA antes da extração, EVA puros (EVA-18 e EVA-28), EVAex e EVAr. Os ensaios foram realizados em um equipamento Shimadzu TGA-50, em uma faixa de temperatura de 100 a $800{ }^{\circ} \mathrm{C}$ com taxa de aquecimento $20^{\circ} \mathrm{C} / \mathrm{min}$ em atmosfera de $\mathrm{N}_{2}(50 \mathrm{~mL} / \mathrm{min})$

\section{Análise das propriedades mecânicas do resíduo de EVA}

Para a determinação das propriedades mecânicas, o resíduo de EVA moído e os EVA virgens (EVA-18 e EVA-28) foram moldados por compressão a $160^{\circ} \mathrm{C}$ e $2 \mathrm{MPa}$ na forma de placas com espessura de $3,2 \mathrm{~mm}$. A partir destas placas, corpos-de-prova foram obtidos e ensaiados segundo as res- 
pectivas normas ASTM: resistência à tração (D638), resistência ao impacto Izod (D256) e dureza (D2240).

\section{Análise morfológica do resíduo}

Amostras de EVA resíduo, EVA resíduo moído, EVA resíduo moído prensado e EVA resíduo prensado seguido de extração de material não reticulado foram analisadas em Microscópio Eletrônico de Varredura (MEV) Jeol JSM-5800. As amostras para os ensaios de MEV foram obtidas a partir da fratura criogênica em nitrogênio líquido dos materiais, na direção transversal. O processo de ataque com solução padrão de ácido crômico para remoção da fase de EVA não reticulada foi realizado como descrito a seguir. A solução foi preparada utilizando-se $16 \mathrm{~g}$ de ácido crômico anidro em $500 \mathrm{~mL}$ de água e completou-se a 1 litro com ácido sulfúrico concentrado com grau de pureza de $95 \%$. As amostras previamente fraturas foram imersas parcialmente em $50 \mathrm{~mL}$ de solução padrão de ácido crômico a temperatura de $70{ }^{\circ} \mathrm{C}$, por um período de 3 horas. Após este período, as amostras foram lavadas com água destilada. Utilizou-se metalização com ouro previamente às análises de MEV.

\section{Resultados e Discussão}

\section{Custo Energético da Moagem do Resíduo de EVA}

Para viabilizar economicamente a reciclagem de materiais é importante o conhecimento do custo do processo na transformação de um novo produto. Desta forma, foi avaliado o custo energético da moagem do resíduo de EVA com base na Equação $1^{[11]}$. Os resultados encontram-se na Tabela 1.

$$
C E=\frac{(P C \times V T)}{C P}
$$

Onde:

$C E=$ Custo energético $(\mathrm{R} \$ / \mathrm{kg})$;

$P C=$ Potência consumida $(\mathrm{kW})$;

$V T=$ Valor da tarifa $(\mathrm{R} \$ / \mathrm{kWh})$;

$C P=$ Capacidade de processamento $(\mathrm{kg} / \mathrm{h})$.

Os dados de mercado fornecem como valor de EVA virgens, R\$ 9,20/kg do EVA com $18 \%$ VAc e R $\$ 9,70 / \mathrm{kg}$ o EVA com $28 \%$ de VAc ${ }^{[12]}$. O custo médio da tarifa energética no estado do Rio Grande do Sul é de R\$ 0,2113/kWh ${ }^{[13]}$. A partir destes dados, o resíduo processado teria um preço inferior a 5\% do valor do EVA virgem, considerando-se somente o custo energético do processo de moagem deste resíduo.

Tabela 1. Valores do consumo energético durante a moagem de resíduos de placas de EVA expandidas

\begin{tabular}{ccc}
\hline Etapas Características & $\begin{array}{c}\text { Potência } \\
(\mathbf{k W h})\end{array}$ & $\begin{array}{c}\text { Custo energético } \\
(\mathbf{R} \$ \mathbf{k g})\end{array}$ \\
\hline Moinho vazio & 6,6 & - \\
Moinho com carga pré-moída & 13,2 & 0,05 \\
Moinho com carga média & 23,0 & 0,09 \\
Moinho com carga bruta & 39,5 & 0,16 \\
\hline
\end{tabular}
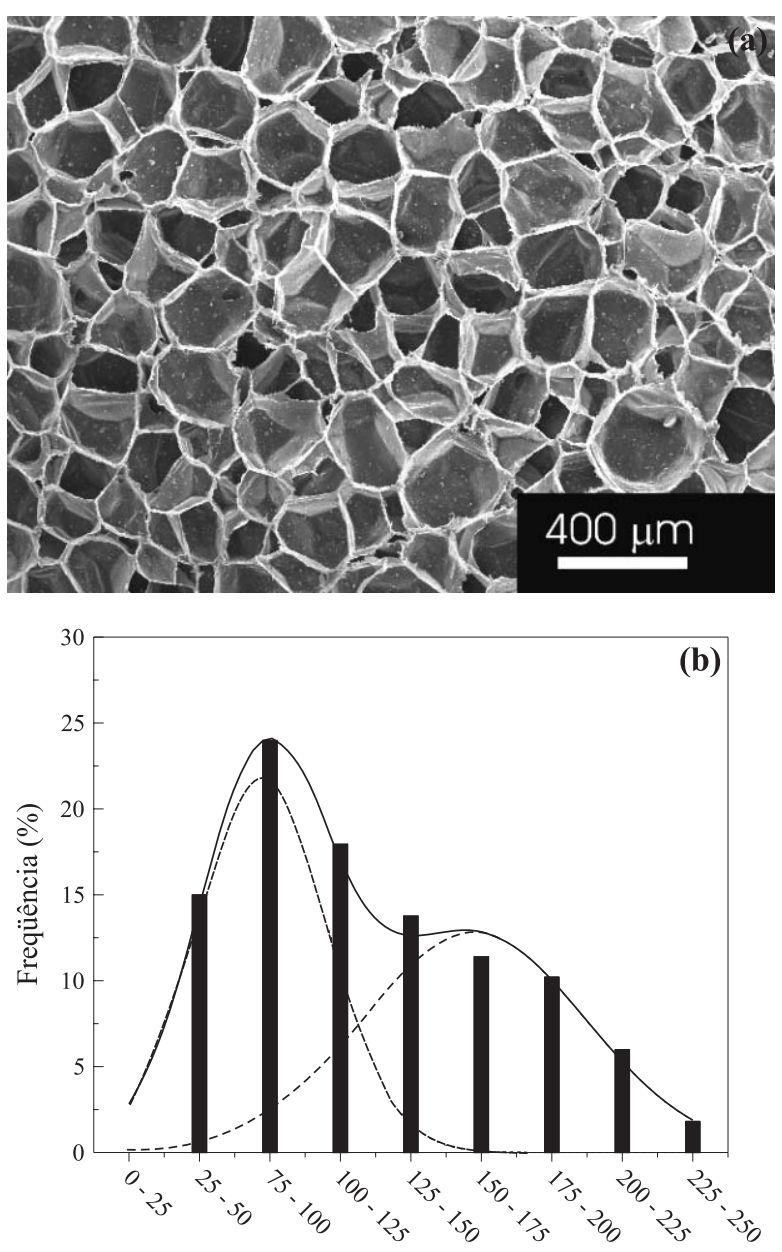

Diâmetro médio dos poros $(\mu \mathrm{m})$

Figura 2. (a) Micrografia de MEV do resíduo de EVA expandido; (b) curva de distribuição de poros

Este resultado é promissor na proposta de reutilização dos resíduos em estudo.

\section{Análise Morfológica do Resíduo de EVA}

$\mathrm{Na}$ Figura 2 são apresentados a micrografia de MEV da superfície de fratura do resíduo de EVA na forma de placa expandida (original) e a correspondente curva de distribuição de poros (análise de imagem). As placas expandidas (Figura 2a) apresentaram morfologia microcelular, com distribuição de tamanhos de poros bimodal (Figura 2b), incluindo uma população com tamanhos da ordem de 25 a $150 \mu \mathrm{m}$ e outra com tamanhos entre 125 e $225 \mu \mathrm{m}$.

Após moagem, como esperado, observou-se a destruição da estrutura celular, formando-se um pó compactado (Figura 3a) com distribuição de tamanhos bimodal (Figura 3b), contendo uma pequena população com tamanhos da ordem de 40 a $100 \mu \mathrm{m}$ e outra população maior com tamanhos entre 50 e $400 \mu \mathrm{m}$.

A análise do resíduo de EVA moído (Figura 4) também identificou a presença de cargas inorgânicas, bastante comum neste tipo de material.

Na Figura 5 são apresentadas as superfícies de fratura do EVA resíduo moído e prensado antes (Figura 5a) e após ata- 

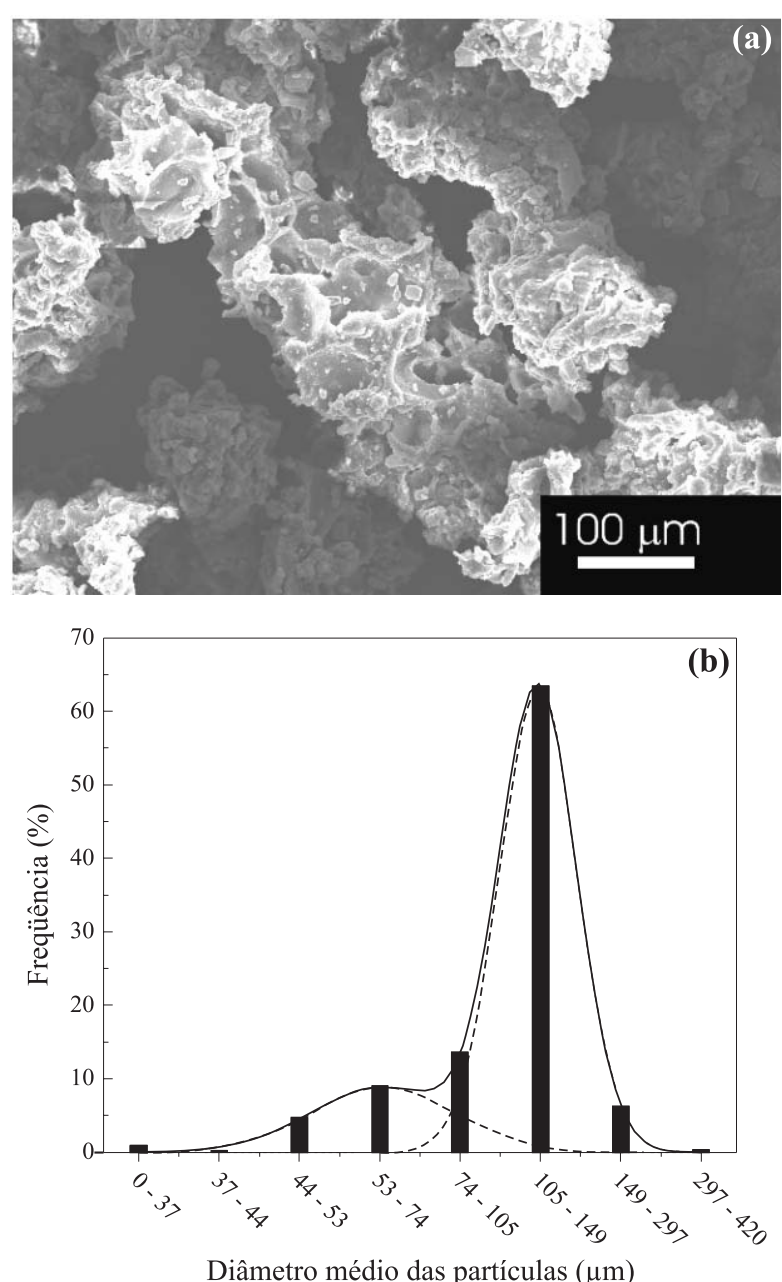

Figura 3. (a) Micrografia de MEV do resíduo de EVA moído; (b) curva de distribuição de tamanhos de partícula

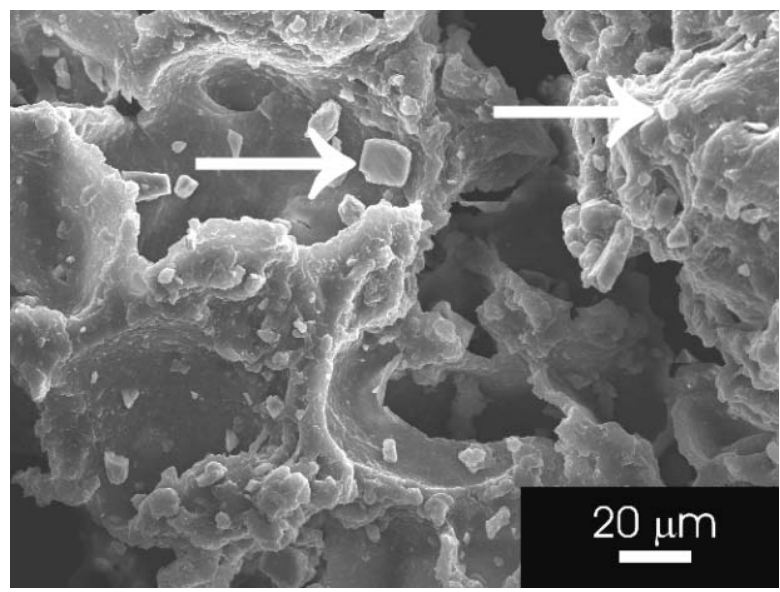

Figura 4. Micrografia (MEV) do EVA resíduo moído com visualização de cargas inorgânicas

que com solução de ácido crômico (Figura 5b). Este tratamento foi utilizado para remoção de material polimérico não reticulado, facilitando a observação das diferentes fases da composição. Pode-se observar que o EVA resíduo consiste em um material composto por uma fase reticulada e uma fase minoritária solúvel (vazios na Figura 5b).
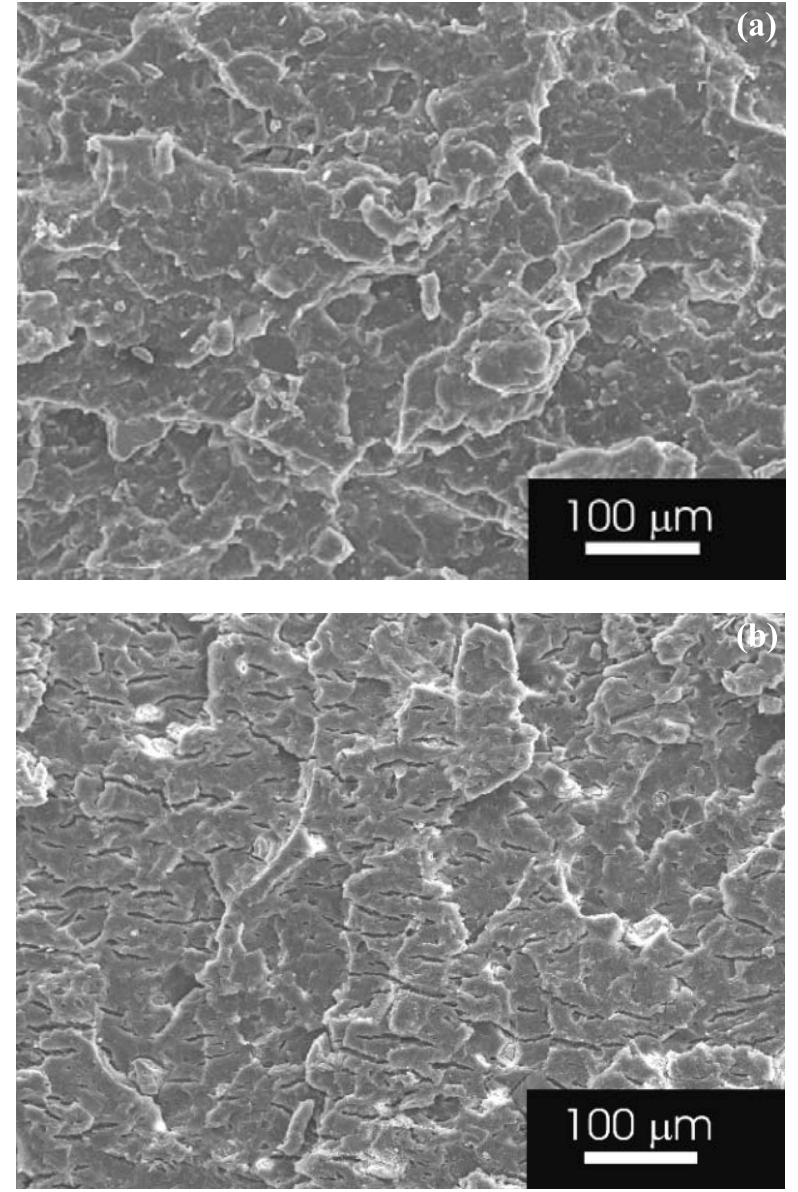

Figura 5. Resíduo de EVA moído e prensado a $160^{\circ} \mathrm{C}$ por 5 minutos (a) antes do ataque químico; (b) após ataque com solução de ácido crômico

\section{Análise termogravimétrica (TGA) e Cálculo do teor de gel}

Na Figura 6 são apresentadas as curvas de TGA do resíduo de EVA após moagem e dos EVA virgens (EVA-18 e EVA28). Para o EVA resíduo e os EVA virgens, pode-se observar duas etapas de degradação, a primeira em torno de 330 a $450{ }^{\circ} \mathrm{C}$ e uma segunda na faixa de temperaturas entre 450 e $520^{\circ} \mathrm{C}$. A primeira etapa está relacionada à degradação de VAc (formação de ácido acético) enquanto que a segunda etapa refere-se à degradação da parte olefínica do copolímero (ligações $\mathrm{C}-\mathrm{C} \mathrm{e}$ $\mathrm{C}-\mathrm{H})^{[14,15]}$. Para o EVA resíduo, pode-se observar adicionalmente uma terceira etapa de degradação $\left(680\right.$ a $\left.750{ }^{\circ} \mathrm{C}\right)$, a qual está relacionada possivelmente à degradação da carga inorgânica presente no resíduo, de acordo com esta faixa de temperatura de degradação. Outro dado interessante que pode ser extraído destas análises é que a porcentagem de carga inorgânica do resíduo é da ordem de $20 \%$ em massa.

As amostras EVAex e EVAr foram também analisadas por TGA e os resultados são mostrados na Figura 7 juntamente com o EVA resíduo. Após extração em xileno, as frações solúvel e insolúvel apresentaram, respectivamente, massas residuais de 2,1 e 25,8\%. Naturalmente, a fração insolúvel contém a carga inorgânica do EVA resíduo.

As medidas de TGA (Figuras 6 e 7) indicam que a massa remanescente no resíduo de EVA moído é de 22,1\%. A par- 


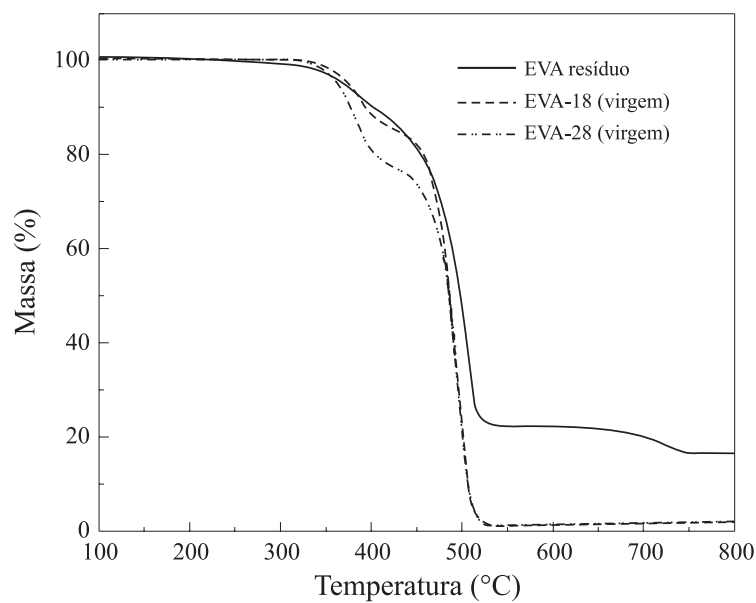

Figura 6. Análise termogravimétrica (TGA) do resíduo de EVA moído (reticulado), do EVA com 18\% de VAc (virgem) e do EVA com $28 \%$ de VAc (virgem)

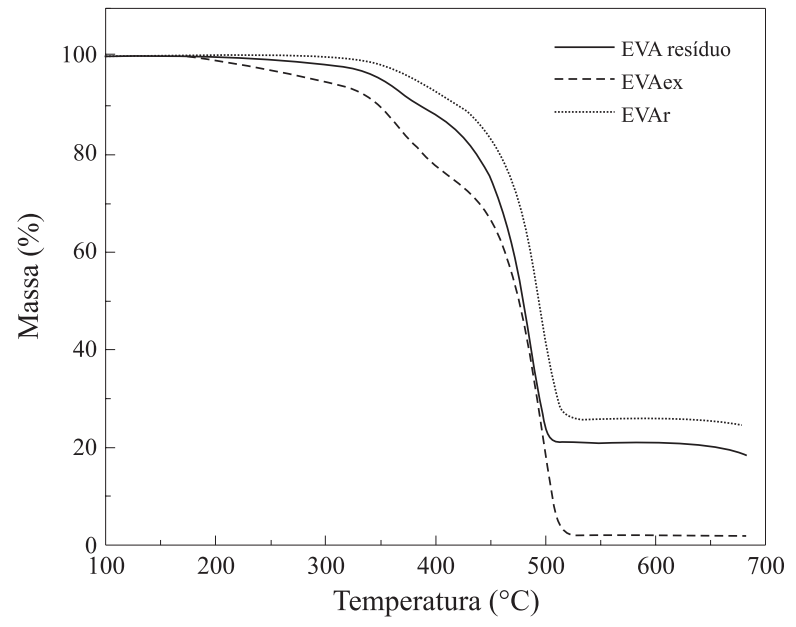

Figura 7. Análise termogravimétrica (TGA) do EVA resíduo, EVAex e EVAr.

tir deste resultado e da análise de teor de gel foi possível calcular o percentual de material reticulado existente (teor de gel) no resíduo estudado (Equação2):

$\%$ de extração de material polimérico $=$

$$
\frac{\% M_{\text {extraida }}}{100-\% M_{\text {residual }}} \times 100=25,2 \%
$$

Onde:

$M_{\text {extraida }}=$ massa percentual extraída no ensaio de determinação de teor de gel;

$M_{\text {residual }}=$ massa percentual residual obtida na análise de TGA.

O teor de gel por definição é dado por [(100) - (\% de extração de material polimérico)]. Assim, o resíduo em estudo possui $74,8 \%$ do material polimérico reticulado, o que é coerente com a relação de massas residuais observadas no TGA para as amostras do EVA resíduo, EVAex e EVAr.

O cálculo do teor de VAc foi realizado a partir do percentual de perda de massa da primeira etapa de degradação (degradação do VAc com formação de ácido acético), conforme método descrito na literatura ${ }^{[14-18]}$.

Os cálculos foram realizados com base na Equação 3 a seguir $^{[16]}$, e os resultados encontram-se na Tabela 2.

$$
T V A c=\frac{M A A c P(\%) \times M M A V}{M M A A c}
$$

Onde:

$T V A c=$ teor de acetato de vinila

$M M A c P(\%)=\%$ de massa de ácido acético perdida fornecida pelos dados de TGA.

$M M A V=$ massa molar de acetato de vinila $(86,1 \mathrm{~g} / \mathrm{mol})$.

$M M A A c=$ massa molar de ácido acético perdido $(60,1 \mathrm{~g} / \mathrm{mol})$.

Os resultados permitem concluir que o EVA resíduo continha originalmente cerca de $28 \%$ em massa de VAc, segundo dado do EVAex, e que este percentual fora reduzido para cerca de $20 \%$ como resultado do processo de reticulação, o qual consome os grupos acetatos.

\section{Propriedades mecânicas}

Na Tabela 3 são apresentados os resultados das propriedades mecânicas do EVA resíduo e dos EVA virgens (EVA-18 e EVA-28), baseados em normas ASTM específicas. Como conseqüência do processo de reticulação, o EVA resíduo possui maior rigidez quando comparado aos EVA virgens. $\mathrm{O}$ EVA resíduo apresentou maiores valores de módulo elástico e de dureza, menores valores de elongação na ruptura e de resistência ao impacto Izod.

\section{Conclusões}

Este trabalho buscou realizar caracterizações morfológica, térmica e mecânica de resíduos de EVA expandidos e

Tabela 2. Perdas de massa, massas residuais, teor de ácido acético decomposto [AA] e de acetato de vinila [VAc] determinados por TGA em amostras do EVA resíduo, EVAr, EVAex, EVA-18 e EVA-28

\begin{tabular}{cccccc}
\hline Amostra & $\begin{array}{c}\mathbf{1}^{\mathbf{a}} \text { perda de massa } \\
(\boldsymbol{\%})\end{array}$ & $\begin{array}{c}\mathbf{2}^{\mathbf{a}} \text { perda de massa } \\
(\boldsymbol{\%})\end{array}$ & $\begin{array}{c}\text { Massa residual } \\
(\boldsymbol{\%})\end{array}$ & $\begin{array}{c}{[\mathbf{A A}]} \\
\mathbf{( \% )}\end{array}$ & $\begin{array}{c}\text { [VAc] } \\
(\boldsymbol{\%})\end{array}$ \\
\hline EVA-18 & 12,4 & 86,3 & 1,3 & 12,8 & 18,0 \\
EVA-28 & 20,6 & 78,1 & 1,3 & 20,9 & 29,9 \\
EVA resíduo & 10,9 & 67,0 & 22,1 & 10,1 & 20,0 \\
EVAex & 19,0 & 78,9 & 2,1 & 19,3 & 27,8 \\
EVAr & 7,6 & 66,6 & 25,8 & 8,2 & 14,7 \\
\hline
\end{tabular}

$*$ a $600^{\circ} \mathrm{C}$ 
Tabela 3. Propriedades mecânicas do EVA resíduo e dos EVA virgens (EVA-18 e EVA-28)

\begin{tabular}{cccc}
\hline Propriedades & EVA-c & EVA-18 & EVA-28 \\
\hline $\begin{array}{c}\text { Módulo elástico (MPa) } \\
\text { Deformação na ruptura } \\
(\%)\end{array}$ & $238 \pm 19$ & $>1200$ & $>1200$ \\
$\begin{array}{c}\text { Resistência ao impacto } \\
\text { Izod (J/m) }\end{array}$ & $179 \pm 9$ & no break & no break \\
$\begin{array}{c}\text { Dureza (Shore D) } \\
\text { Dure, }\end{array}$ & $48 \pm 2$ & $43 \pm 1$ & $33 \pm 1$ \\
\hline
\end{tabular}

reticulados provenientes da indústria de calçados. Análise em MEV permitiu caracterizar a morfologia microcelular do EVA resíduo a qual, após o processo de moagem, é destruída. Segundo análise em MEV, o resíduo de EVA moído apresenta duas fases, uma reticulada (matriz) e uma não-reticulada (dispersa). O resíduo de EVA moído apresentou teor de gel de aproximadamente $75 \%$ em massa, segundo medidas de extração da fase solúvel em xileno. Através de medidas de TGA pode-se verificar que o EVA resíduo possui cerca de $20 \%$ em massa de acetato de vinila (VAc) e que fora processado possivelmente a partir de EVA com teor de VAc de aproximadamente $28 \%$. Dados de TGA também permitiram determinar o teor de carga inorgânica existente ( $20 \%$ em massa). Análises das propriedades mecânicas do EVA resíduo demostraram que este material apresenta maior rigidez quando comparado ao EVA virgem, com maiores valores de módulo elástico e de dureza, e menores valores de elongação na ruptura e de resistência ao impacto Izod. Portanto, os resultados obtidos evidenciam que o processo de reticulação do EVA altera suas propriedades térmicas e mecânicas. O custo energético da moagem do resíduo de EVA foi calculado como sendo inferior a 5\% do valor do EVA virgem. A caracterização do resíduo de EVA elaborada neste trabalho é relevante para propósitos de reciclagem mecânica deste material.

\section{Agradecimentos}

Os autores agradecem ao CNPq, FAPERGS, Sindicato das Indústrias Calçadista de Três Coroas pelo apoio financeiro e Prof. Dra. Regina Célia Reis Nunes pelas correções e sugestões .

\section{Referências Bibliográficas}

1. Yamaki, S. B.; Prado, E. A. \& Atvars, T. D. Z. - European Polymer Journal, 38, p.1811-1826 (2002).
2. Informações \& Noticias., "Versatilidade de EVA Conquista Mercado"-Polímeros Ciência e Tecnologia, vol 13, n² (2003).

3. Sakai, R. H. - Tecnicouro, 13(6), p.39-42 (1991).

4. Rohde, E. - Rubber World,may, 5, p.36-58 (1993).

5. Correia, J. - Tecnicouro, 12(1), p.51(1990).

6. Associação Brasileira da Indústria do Plástico - ABIPLAST, "A Indústria Brasileira da Transformação de Material Plástico- Perfil 2003" (2004).

7. Serrano, C. L. S. - "Mapeamento dos Resíduos Poliméricos Produzido pela Indústria Calçadista na Região do Vale do Rio dos Sinos", in Anais do $6^{\circ}$ Congresso Brasileiro de Polímeros, Gramado, p.1796-1799 (2001).

8. Dariva, J. J. \& Luca, S. J. - "Gerenciamento Ambiental de Resíduos Sólidos Industriais, caso de Estudo - 113 Indústrias Calçadista de Três Coroas - RS", in Anais do $20^{\circ}$ Congresso Brasileiro de Engenharia Sanitária e Ambiental, Rio de Janeiro, p.1987-1994 (1999).

9. Buffon, C. \& Gonsalez, W. - "Materiais - Solados e Palmilhas de Montagem", Centro Tecnológico do Couro, Calçados e Afins - CTCCA, p.56-72 (2002).

10. Tatibouët, J.; Gendron, R. \& Haïder, L. - Polymer Testing, 23, p.125-130 (2004).

11. Zattera, A. J.; Almeida, M. G.; Mondadori, N. L. \& Zeni, M. - Revista Información Tecnológica del Chile, La Serena - Chile, p.103-106 (1997).

12. Dados fornecidos pela empresa COPLASUL.

13. Dados da Companhia Rio Grande Energia (RGE) (2004).

14. Lucas, E. F.; Soares, B. G. \& Monteiro, E. - "Caracterização de polímeros - Determinação de peso molecular e Análise térmica", E-papers Serviços Editorais (2001).

15. McGrattan, B. J. - American Chemical Society, p.102115 (1994).

16. Hull, T. R.; Price, D.; Liu, Y.; Wills, C. L. \& Brady, J. Polymer Degradation and Stability, 82, p.365-371 (2003).

17. Marcilla, A. \& Beltrán, M.- Polymer Degradation and Stability, 50, p.117-124 (1995).

18. Mothé, C. G. \& Tavares, M. I. - Polymer Degradation and Stability, 57, p.183-186 (1977).

Enviado: 05/10/04

Reenviado: 27/12/04

Aprovado: 04/01/05 